Research Article

\title{
Grey Weighted Sum Model for Evaluating Business Environment in West Africa
}

\author{
Moses Olabhele Esangbedo and Ada Che \\ School of Management, Northwestern Polytechnical University, Xian 710072, China \\ Correspondence should be addressed to Ada Che; ache@nwpu.edu.cn
}

Received 9 January 2016; Revised 17 April 2016; Accepted 4 May 2016

Academic Editor: Rafael Morales

Copyright ( 2016 M. O. Esangbedo and A. Che. This is an open access article distributed under the Creative Commons Attribution License, which permits unrestricted use, distribution, and reproduction in any medium, provided the original work is properly cited.

As West Africa investments grow, the decision in which country to begin investment is of great importance to investors. The complexity of the criteria involved draws us to use a Multicriteria Decision-Making (MCDM) approach to address this problem. In this paper, we use grey numbers in representing ranges of data and propose Grey Weighted Sum Model (GWSM) for evaluating and ranking of alternatives. Sensitivity analysis is carried out considering wide ranges of uncertainties to verify the changes that can affect the results. The Gambia is ranked the best country in West Africa. The GWSM is highly recommended for long-term investors because GWSM considers the uncertainty of a business environment over a period of years. Finally, GWSM can be used in conjunction with various weighting techniques putting the preferences of the investors into consideration.

\section{Introduction}

West Africa is becoming part of the growing economy, and it is a land of opportunities. The Economic Community of West African States (ECOWAS) includes 15 member countries rich in mineral resources and with millions of consumers. As businesses grow and want to expand their services to more countries, the country to begin investment is very important to the investors. The ability to rank a country in relation to others after evaluating their business environment gives an investor a quick insight in making a decision on where to invest its resources for a good turnover. A poor decision can easily lead to business failure and a huge loss to the investor. Thus, the techniques and approaches for evaluating the business environment of various countries are indispensable. Not only does the investor benefit from businesses but also it plays a significant role in the growth of poorer countries [1].

For businesses to be successful, there is a need to balance short-term and long-term goals in an uncertain business environment like West Africa. There are some levels of doubt for an entrepreneur who has not invested in West Africa. Selecting the country to invest in West Africa becomes complicated across these countries considering several criteria and the level of unequal uncertainties. One of the symptoms of a poor decision is ignoring uncertainties [2]. When doing business in West Africa, uncertainties should be analysed and anticipated. Every good Decision Maker (DM) knows that there are uncertainties investing in West Africa. However, when these uncertainties are considered in decision-making, it increases the DM's confidence on the decision outcome [3].

The World Bank (WB) launched the Doing Business Project (DBP) in 2002, making available annual objective measures of business regulations and their enforcement across 189 economies to the public. The DBP delivers the ranking of various countries' business environment annually. The data provided by DBP/WB encourages countries to work towards better regulations and reform benchmarks. Also, the data provides resources for academics, journalists, researchers, and those interested in the business environment of various countries [4]. However, the ranking values provided by the DBP are annual values that do not reflect the business environment performances over a period of years. Since most businesses are not expected to survive for just a year of operations, it can be erroneous for investors to make a decision from a single year of objective measures and ranking of the business environments, especially for the long-term investment.

The evaluation of business environment is addressed using Multicriteria Decision-Making (MCDM) approach, which can handle multiple conflicting criteria and closely 
related alternatives. Future data cannot be known from only current data, but it is most likely that future data may be within the ranges of already known past and current data, which are represented as interval grey numbers. Although the uncertainties of the future are absolute, grey numbers are used to model the uncertainties of the future caused by incomplete and insufficient information in making an investment decision. This paper proposes an original approach, called Grey Weighted Sum Model (GWSM), in evaluating the business environment in West Africa by accounting for uncertainties over a period of years. The contributions in this paper are twofold. Firstly, we address a major problem not covered by the DBP, that is, ranking countries over a period of years considering the degree of uncertainty in the country as well as investors preferences represented as criteria weights. Secondly, we extend the traditional Weighted Sum Model (WSM) by using grey numbers to represent performances of evaluation criteria that may vary from time to time.

This work is presented as follows. Section 2 is Literature Review and Section 3 is Grey Weighted Sum Model (GWSM). Section 4 presents the results and some discussions. The sensitivity analysis using GWSM is given in Section 5. Finally, a conclusion is drawn in Section 6.

\section{Literature Review}

There are several methods for solving and evaluating selection problems in MCDM [5-7]. Some of these methods include the Analytical Hierarchy Process (AHP) developed by Thomas Saaty for evaluating alternatives by comparing all the criteria of the alternatives [8]. The Analytical Network Process (ANP) was later introduced by Thomas Saaty as a method to evaluate alternatives with interdependent decision criteria and alternatives [9]. Zavadskas et al. developed the COmplex PRoportional ASsessment (COPRAS) for evaluating alternatives which measure the complex efficiency of an alternative as a proportion of the minimum and maximum criteria values $[10,11]$. Data Envelopment Analysis (DEA) is a method for evaluating the effective efficiency of decision-making unit. Shakouri et al. [12] used the DEA in conjunction with Simple Additive Weighting (SAW) to assess power supply technologies. Elimination and Choice Expressing Reality (ELECTRE) was developed as early as in the 1960s [13] and has had more than four major iterative improvements to address the problem of not being able to rank alternatives. Several improvements that have been introduced to ELECTRE include ELECTRE I-IV, ElECTREIS, and ELECTRE-TRI [14]. Technique for Order Preferences by Similarity to an Ideal Solution (TOPSIS) was introduced by Hwang and Yoon [15] in selecting the best alternative as a compromise solution. TOPSIS method selects the alternative with the shortest distance to the ideal solution and farthest distance to the negative ideal solution; these distances are usually measured as Euclidean distances. Evidential Reasoning Approach (ERA) [16] evaluates alternatives with qualitative and quantitative criteria based on Dempster-Shafer (DS) theory of evidence [17] with some level of ignorance. Grey Relational Analysis (GRA) [18] is based on the Grey System Theory (GST) and uses the relative relational coefficient of evaluation alternatives to the ideal alternative in determining the best alternative. Multiattribute Utility Theory (MAUT) [19] is a classical method for evaluating alternatives by aggregating the satisfaction obtainable from every criterion measured as utils. Preference Ranking Organization Method for Enrichment of Evaluation (PROMETHEE) [20] was developed by Jean-Pierre Brans, which is an outranking method. Researchers have widely accepted PROMETHEE, and they have developed it to a fully ranking technique. Superiority and Inferiority Ranking (SIR) [21] is a combination of the WSM and PROMETHEE, where WSM is used for aggregation of procedure and PROMETHEE for ranking procedures. Simple Multiattribute Rating Technique (SMART) [22] is an MCDM method in which the DM assigns points to every criterion for all alternatives as well as the relative criteria for estimating the weights for evaluation. SMART Extended to Ranking (SMARTER) [23] is an improvement of SMART by using rankings of the criteria for weight estimation.

The relative importance of evaluation criteria for an MCDM problem is expressed using weights by the DM(s). With clear goal and alternatives, the method of assigning weights to the evaluation criteria must be determined by making sure that it can produce the most accurate ratio of the criteria based on the relative levels of importance. Subjective or objective weighting methods [24] for MCDM problems can be used in determining the weights. For instance, group decision-making process can be used in estimating the weights, as well as the introduction of linguistic value because of the way humans think [25]. Li et al. [26] applied grey arithmetic mean weighting method in aggregating the group weights of DMs in software selection. Wang [27] applied this same technique to the selection of personnel using grey linguistic values for measuring the preferences of the group DMs. Similarly, Bai and Sarkis, Kose et al., Kuang et al., and Mehrjerdi [28-31] all used grey arithmetic mean in computing the weights of criteria in a group decision-making environment. Kang et al. [32] applied grey geometric mean in aggregating the weights of the DMs to determine the suitable meeting location based on the service offered and the preferences of the DMs. Grey correlation operators can be used to compute the relationships among all the DMs preferences and assign weights to the criteria based on the dependences in the relationship of the preferences [33]. Other grey correlation operators are Interval Grey Linguistic Variables Ordered Weighted Aggregation (IGLOWA), Interval Grey Linguistic Correlated Ordered Arithmetic Aggregation (IGLCOA), and Interval Grey Linguistic Correlated Ordered Geometric Aggregation (IGLCOGA) [34]. Jin et al. [35] estimated the weights of the criteria using grey harmonic operators, which is based on the number of occurrences of the weights assigned by the group of DMs. Esangbedo and Che [36] proposed the Grey Rank Order Centroid (GROC) weights for group decision-making and applied it to evaluate African business environment in a specific year, rather than over a period of several years addressed in this study, based on the GRA method.

The main techniques closely related to this paper are WSM and GST. WSM can be described as a weighted linear combination or scoring method $[37,38]$. The WSM is also 
called SAW, and for consistency in this paper we use the term WSM for both WSM and SAW [39, 40]. WSM is a representation of the DM's preferences in a linear additive function [41]. Triantaphyllou and Mann [42] examined the effectiveness of decision-making methods and pointed WSM as one of the simplest methods for solving MCDM problems. The best alternative is the one with the maximum score satisfying (1) after transforming all measurement criteria to a single dimension:

$$
A_{\mathrm{WSM}}^{*}=\max _{1 \leqslant i \leqslant m} \sum_{j=1}^{n} a_{i j} w_{j},
$$

where $A_{\text {WSM }}^{*}$ is the score of the best alternative, $a_{i j}$ represents the value of the $j$ th criterion of the $i$ th alternative, and $w_{j}$ corresponds to the weight of the $j$ th criterion, where $1 \leq i \leq$ $m$ and $1 \leq j \leq n$.

From (1), the intuitive nature and ease of dealing with MCDM problems can be seen, and this simplicity makes WSM one of the most important methods for both exploring possible solutions for an MCDM problem and providing solutions in comparison to other methods [5]. A lot of MCDM methods, including the AHP and PROMETHEE, use weighted sum aggregation technique in selecting the best alternative [38]. Structuring of an MCDM problem can easily be done using WSM by making sure that the problem has a clear objective, criteria, and alternatives. The standardized scores using the WSM have an equal relative order of magnitude because the linear transformation is proportional to the raw data. The simplicity of implementation provided by the WSM is a form of transparency of the model to the DMs [43]. WSM method has been improved and applied in many areas over the years. Goh et al. [44] introduced revised weighted method to WSM to reduce the effect of enormous dissimilar decision preferences on the decision results by eliminating the minimum and maximum rates on the decision criteria during the evaluation process. Triantaphyllou and Lin [45] introduced fuzzy numbers and WSM combination approach. In simplifying the complexity and reducing the round-off errors introduced by using fuzzy numbers in WSM, Modarres and Sadi-Nezhad [46] used preferences ratios in comparing fuzzy numbers. Chou et al. [40] proposed a fuzzy simple additive weighting system in determining the best location for facilities in a group decision-making environment. Zavadskas et al. [47] combined weighted product model and WSM to form an evaluation method called Weighted Aggregated Sum Product Assessment (WASPAS). Then Zavadskas et al. further extended WASPAS to interval-valued intuitionistic fuzzy numbers as well as grey numbers because of the vagueness in human judgement and preferences [48, 49]. Stanujkic and Zavadskas [50] introduced compensation coefficient values to WSM helping DMs select among the best ranking alternatives and the alternatives that best meet their preferences. Chen [51] applied WSM in group decision-making by using interval type-2 fuzzy sets for linguistic and incomplete preference measurement. Wang [52] addressed the drawback of fuzzy multiplication in WSM by using relative preferences to represent the weights of the criteria. Zamri and Abdullah [53] combined linear programming and WSM in the context of an interval fuzzy set for ranking alternatives. Xu et al. [54] proposed a discrete model for conflict-elimination for determining the weights of group experts in decision-making and applied it to WSM in choosing the best alternative.

GST is a mathematical concept of grey set developed by Professor Deng [55]. GST is a method capable of solving uncertain problems with incomplete information and discrete data. GST deals with information between a black and a white part, which represent unknown and known information, respectively. GST has different sections that include GRA, grey decision, grey programming, grey prediction, and grey control. Grey numbers are used in representing systems with incomplete information. GST has been applied in business management like project management and planning, as well as the stock market and portfolio selection [18, 56, 57]. When considering MCDM with the advancement to grey numbers, $\mathrm{Xu}$ and Sasaki [58] extended the technique of order preference by similarity to ideal and anti-ideal alternatives by measuring the closeness coefficient to the ideal alternative using grey numbers. Li et al. [59] used arithmetic mean for group weights of Grey Possibility Degree (GPD) that provides the position relationship between two grey numbers for ranking. Turskis and Zavadskas [60] applied grey number in Additive Ratio Assessment (ARAS) for ranking. ARAS is a ratio of the optimal value of the alternatives to the optimal value of the ideal alternative resulting to utility degrees. Liu et al. [61] proposed a method for ranking interval numbers based on a normal distribution and used it to optimize the mining methods. Mousavi et al. [62] addressed the problem of uncertainty in multicriteria optimization and compromised solution by using grey numbers in VIKOR method for ranking material handling equipment. VIKOR is an acronym for the Slovenian phrase "VlseKriterijumska Optimizacija I Kompromisno Resenje in Serbian" which means multicriteria optimization and compromise solution. In contrast to TOPSIS, VIKOR calculates the relative alternative distance to the ideal solution. Oztaysi [63] combined grey number with AHP for weighting the criteria and used TOPSIS ranking method for the selection of Content Management System (CMS).

Zavadskas et al. [64] proposed Simple Additive Weighting with Grey (SAW-G) number and applied it in contractor selection for construction works. Also, SAW-G was applied in evaluating the performance of rural ICT centers in Iran [65]. Nonetheless, the SAW-G technique does not completely show the degree of uncertainty in ranking because the boundary distances between the lower and upper bounds of the grey numbers are not considered in the evaluation. For example, suppose the evaluated investment outcome measured in units for the first and the second investment alternatives represented by grey numbers are $\otimes I_{1}=[i, 7 i]$ and $\otimes I_{2}=$ $[3 i, 5 i]$, respectively. That is, the investment outcomes of the first alternative is between $i$ and $7 i$ and the second alternative is between $3 i$ and $5 i$. Using the SAW-G technique, the white value of these two investments is $4 i$. Although these investments have the same white value, the degrees of uncertainties are not equal. From the grey numbers, the first investment has a greater degree of uncertainty than the second investment. In other words, we are more guaranteed about the outcome of the second investment. The GWSM addresses this limitation. 


\section{Grey Weighted Sum Model}

GWSM is an extension of the WSM based on grey numbers. For this model, we use an interval type of grey numbers to model the uncertainties. A grey number with lower and upper bounds is called an interval grey number and it is represented as $\otimes G=[g, \bar{g}]$, where $g$ and $\bar{g}$ denote its lower and upper bounds, respectively. Some basic operations of two grey numbers $\otimes G=[\underline{g}, \bar{g}]$ and $\otimes H=[\underline{h}, \bar{h}]$, where $\underline{h}$ is the lower bound and $\bar{h}$ is the upper bound, are as follows $[66,67]$ :

$$
\begin{aligned}
& \otimes G+\otimes H=[\underline{g}+\underline{h}, \bar{g}+\bar{h}], \\
& \otimes G-\otimes H=[\underline{g}-\bar{h}, \bar{g}-\underline{h}], \\
& \otimes G \times \otimes H=[\underline{g}, \bar{g}] \times[\underline{h}, \bar{h}]=[\underline{g} \underline{h}, \bar{g} \bar{h}] .
\end{aligned}
$$

If $g$ is a white value, that is, a real number or crisp values,

$$
g \times \otimes H=[g \underline{h}, g \bar{h}] .
$$

The traditional WSM makes use of real numbers for the evaluation of alternatives. Interval number is a form of uncertain values, and GST deals with uncertain values that are represented as interval grey numbers $[68,69]$. The main goal of considering uncertainty in decision-making is to provide the DMs with a holistic view of the decision problem to deliberate and reason confidently [70]. In dealing with uncertainty in decision-making, introducing GST to WSM is introducing reasonable slacks to the performance of the alternative that will be used in the evaluation for decision-making. Business environment is dynamic; for example, government policies, natural environment, taxes, interest, and exchange rates do change. GST is designed to analyse systems with incomplete information and systems whose ranges of performances are known. These ranges are represented as grey numbers. In the traditional WSM, the values of the criteria and weights are fixed values, but for some MCDM problems, the performances of criteria may vary within a range of values. WSM cannot be used to evaluate alternatives with varying performances of the decision criteria. The inability for the WSM to evaluate alternatives with uncertain criteria measurement represented as interval numbers is the limitation of the traditional WSM that the GWSM addresses. The primary concept of GWSM is using weighted grey numbers of the evaluation criteria for the assessment of alternatives and putting the degree of uncertainty into consideration using the boundary distance of the criteria. Its main procedure is explained as follows. Firstly, we construct a grey decision matrix and calculate a normalized grey decision matrix. Then, we aggregate the weighted normalized grey decision matrix to obtain a grey value for all alternatives. Next, the boundary distances of the alternatives are calculated and used in estimating the white values. Lastly, these white values are ranked to determine the best alternative. The GWSM steps are given below.
Step 1 (construct the grey decision matrix). The decision matrix $X$ is represented by

$$
X=\left(\begin{array}{cccc}
\otimes x_{11} & \otimes x_{12} & \cdots & \otimes x_{1 n} \\
\otimes x_{21} & \otimes x_{22} & \cdots & \otimes x_{2 n} \\
\vdots & \vdots & \ddots & \vdots \\
\otimes x_{m 1} & \otimes x_{m 2} & \cdots & \otimes x_{m n}
\end{array}\right),
$$

where $\otimes X_{i j}=\left[\underline{x}_{i j}, \bar{x}_{i j}\right]$, which represents the grey number of the $j$ th criterion of the $i$ th alternative. Also, every alternative can be written in a vector form:

$$
X_{i}=\left(\otimes x_{i, 1}, \otimes x_{i, 2}, \ldots, \otimes x_{i, n}\right) .
$$

Step 2 (normalize the grey decision matrix). The normalization step is to make the criteria measurement in the same direction. Cost and benefits preferences are in two directions of measurement. For the benefits preferences, that is, the higher the value, the better the value, they are normalized as follows:

$$
\begin{aligned}
\otimes x_{i j}^{*}= & {\left[\frac{\underline{x}_{i j}-\min _{1 \leq i \leq m} \underline{x}_{i j}}{\max _{1 \leq i \leq m} \bar{x}_{i j}-\min _{1 \leq i \leq m} \underline{x}_{i j}},\right.} \\
& \left.\frac{\bar{x}_{i j}-\min _{1 \leq i \leq m} \underline{x}_{i j}}{\max _{1 \leq i \leq m} \bar{x}_{i j}-\min _{1 \leq i \leq m} \underline{x}_{i j}}\right] .
\end{aligned}
$$

For the cost preferences, that is, the smaller the value, the better the value, they are normalized as follows:

$$
\begin{aligned}
\otimes x_{i j}^{*}= & {\left[\frac{\max _{1 \leq i \leq m} \bar{x}_{i j}-\bar{x}_{i j}}{\max _{1 \leq i \leq m} \bar{x}_{i j}-\min _{1 \leq i \leq m} \underline{x}_{i j}},\right.} \\
& \left.\frac{\max _{1 \leq i \leq m} \bar{x}_{i j}-\underline{x}_{i j}}{\max _{1 \leq i \leq m} \bar{x}_{i j}-\min _{1 \leq i \leq m} \underline{x}_{i j}}\right] .
\end{aligned}
$$

Then, a normalized decision matrix is constructed:

$$
X^{*}=\left(\begin{array}{cccc}
\otimes x_{11}^{*} & \otimes x_{12}^{*} & \cdots & \otimes x_{1 n}^{*} \\
\otimes x_{21}^{*} & \otimes x_{22}^{*} & \cdots & \otimes x_{2 n}^{*} \\
\vdots & \vdots & \ddots & \vdots \\
\otimes x_{m 1}^{*} & \otimes x_{m 2}^{*} & \cdots & \otimes x_{m n}^{*}
\end{array}\right) .
$$

In a vector form, we define

$$
X_{i}^{*}=\left(\otimes x_{i, 1}^{*}, \otimes x_{i, 2}^{*}, \ldots, \otimes x_{i, n}^{*}\right) .
$$

Step 3 (determine the weights of the criteria). The weights $W$ used for the criteria are those assigned by experts or obtained from the DMs using any of the techniques in Section 2. Either grey weights or white (crisp) weights, that is, weights in real numbers, can be used in this step. Ideally, grey weights should be used when there is some level of uncertainties about the weights.

For grey weights,

$$
W=\left(\otimes W_{1}, \otimes W_{2}, \ldots, \otimes W_{n}\right)^{T},
$$


where $\otimes W_{j}=\left[\underline{w}_{j}, \bar{w}_{j}\right]$ and $\underline{w}_{j}$ and $\bar{w}_{j}$ are the weight's lower and upper bounds of the $j$ th criterion. The weights are scaled such that the summation of the upper bounds of the scaled weights is a unit value. The weights are scaled using

$$
\otimes W_{j}^{\prime}=\frac{\otimes W_{j}}{\sum_{j=1}^{n} \bar{w}_{j}},
$$

where $\otimes W_{j}^{\prime}=\left[\underline{w}_{j}^{\prime}, \bar{w}_{j}{ }_{j}\right]$ and $\sum_{j=1}^{n}{\overline{w^{\prime}}}_{j}=1$.

Therefore, the scaled grey weight is

$$
W^{\prime}=\left(\otimes W_{1}^{\prime}, \otimes W_{2}^{\prime}, \ldots, \otimes W_{n}^{\prime}\right)^{T}
$$

For white (crisp) weights,

$$
W=\left(w_{1}, w_{2}, \ldots, w_{n}\right)^{T},
$$

where $w_{j}$ is the weight of the $j$ th criteria. Then, after scaling, we have

$$
W^{\prime}=\left(w_{1}^{\prime}, w_{2}^{\prime}, \ldots, w_{n}^{\prime}\right)^{T}
$$

where $w_{j}^{\prime}=w_{j} / \sum_{j=1}^{n} w_{j}$ and $\sum_{j=1}^{n} w_{j}^{\prime}=1$.

Step 4 (aggregate the weighted decision matrix). This step is the sum of the weighted normalized criteria for all the alternatives:

$$
Y=X^{*} \times W^{\prime}
$$

For grey weights,

$$
Y=\left(\begin{array}{cccc}
\otimes x_{11}^{*} & \otimes x_{12}^{*} & \cdots & \otimes x_{1 n}^{*} \\
\otimes x_{21}^{*} & \otimes x_{22}^{*} & \cdots & \otimes x_{2 n}^{*} \\
\vdots & \vdots & \ddots & \vdots \\
\otimes x_{m 1}^{*} & \otimes x_{m 2}^{*} & \cdots & \otimes x_{m n}^{*}
\end{array}\right)\left(\begin{array}{c}
\otimes W_{1}^{\prime} \\
\otimes W_{2}^{\prime} \\
\vdots \\
\otimes W_{n}^{\prime}
\end{array}\right) .
$$

For white (crisp) weights,

$$
Y=\left(\begin{array}{cccc}
\otimes x_{11}^{*} & \otimes x_{12}^{*} & \cdots & \otimes x_{1 n}^{*} \\
\otimes x_{21}^{*} & \otimes x_{22}^{*} & \cdots & \otimes x_{2 n}^{*} \\
\vdots & \vdots & \ddots & \vdots \\
\otimes x_{m 1}^{*} & \otimes x_{m 2}^{*} & \cdots & \otimes x_{m n}^{*}
\end{array}\right)\left(\begin{array}{c}
w_{1}^{\prime} \\
w_{2}^{\prime} \\
\vdots \\
w_{n}^{\prime}
\end{array}\right) .
$$

Therefore,

$$
Y=\left(\begin{array}{c}
\otimes y_{1} \\
\otimes y_{2} \\
\vdots \\
\otimes y_{m}
\end{array}\right)
$$

where $\otimes y_{i}=\left[y_{i}, \bar{y}_{i}\right]$ is a grey number, which represents the weighted sum of all the criteria for the $i$ th alternative.
Step 5 (obtain the white values of the alternatives). This step is key in transforming the grey number to a white number. Whitenization is conducted using the following equation:

$$
V_{i}=\underline{y}_{i}(1-\lambda)+\bar{y}_{i} \lambda \text {, }
$$

where the whitenization coefficient $\lambda \in[0,1]$.

Step 6 (determine the boundary distance of the alternatives). In this step, we calculate the degree of uncertainty, $S_{i}$, for the $i$ th alternative. $S_{i}$ is defined as follows:

$$
S_{i}=\sqrt[p]{\left(\bar{y}_{i}\right)^{p}-\left(\underline{y}_{i}\right)^{p}}
$$

when $p=1$, the boundary distance is the Manhattan distance; when $p=2$, the boundary distance is the Euclidian distance; and when $p=3$, the boundary distance is the Minkowski distance with 3rd degree.

As $S_{i}$ tends to zero, theoretically, the stability of the outcome for the future investment tends to $100 \%$. In other words, there is no uncertainty.

Step 7 (rank the alternatives). In ranking the alternatives, the uncertainty of the white value obtained in Step 5 is considered in calculating the rank scores. Knowing the degree of uncertainty, we can estimate the degree of certainty since the sum of both degrees is a value of one. The rank score is the product of the white value and the degree of certainty as follows:

$$
z_{i}=V_{i}\left(1-S_{i}\right)
$$

From the above formula, as uncertainty decreases and the white value increases, then the rank score increases, resulting in a better rank value. From the rank scores, relative percentage rank scores of all alternatives to the best score are also calculated. The alternative with $100 \%$ is the best alternative. Percentage rank scores are computed as follows:

$$
Z_{i}=\left[\frac{z_{i}}{\max \left(z_{i}\right)}\right] \times 100 .
$$

We note that the above procedure is similar to the one proposed by Zavadskas et al. [64, 65]. However, we take into account the degree of uncertainty and grey weights in our procedure. It is not uncommon to see hybrid approaches in solving MCDM problems, for example, Fuzzy-AHP, FuzzyTOPSIS, Grey-AHP, and Grey-TOPSIS [71-74]. The approach we propose above can be combined with different weighting approaches to form several hybrid methods, for instance, using fuzzy weight method to form a fuzzy-GWSM and pairwise comparison weighting method to form an AHP-GWSM method.

\section{Results and Discussion}

In this study, we use GWSM method for evaluating business environment of West African countries. Weights help to recognize the relative importance of the decision criteria, and they have a direct influence on the ranking of alternatives. 
Measuring the weights of criteria is part of the problem in the evaluation of alternatives; the DBP used equal weights in evaluating these countries. The preferences of some investors are used to estimate the weights of the evaluation criteria using the GWSM method. We use the region of West Africa for our sample, and the data for these countries are obtained from the DBP database, which are then transformed to grey numbers. The transformation is done by using the lowest and highest measurement values of these countries for every criterion between the year 2008 and the year 2015 as the lower and upper bounds of the grey number. The grey numbers of these criteria and the weights are aggregated to give the weighted grey number for each country. Ranking operations are done using GWSM method, and sensitivity analysis is carried out to obtain ranges of ranking results.

4.1. Evaluating Business Environment in West Africa. For this work, we focus on West African countries. According to Encyclopædia Britannica [75], the western African countries include Benin, Burkina Faso, Cameroon, Cape Verde, Chad, Côte d'Ivoire, Equatorial Guinea, the Gambia, Ghana, Guinea, Guinea-Bissau, Liberia, Mali, Mauritania, Niger, Nigeria, Senegal, Sierra Leone, and Togo. In total, 19 countries are evaluated. These countries are indexed from 1 to 19 in alphabetical order, Benin has an index number of 1, Burkina Faso has an index number of 2 , and Togo has an index number of 19 .

The decomposition of a complex problem into a hierarchy is a very common method for solving problems similar to the "divide and conquer" approach. Table 1 shows a hierarchy of the evaluation criteria given by the DBP [36, 76]. The hierarch, the goal, is "Business Environment of Countries." The first-level hierarchy is the first-level criteria and the second-level hierarchy is the second-level criteria. The second-level criteria are indexed from 1 to 37 as given in Table 1. The DBP gives a comprehensive explanation of these criteria at http://www.doingbusiness.org/methodology. These countries are evaluated based on the criteria presented by the DBP.

Using the GWSM, we present an evaluation of the business environment in West Africa. Following the steps in the previous section, the evaluation is presented below.

Step 1 (construct the grey decision matrix). The decision criteria are shown in Table 1. There are in total 37 secondlevel criteria indexed from 1 to 37 . The values of the secondlevel criteria obtained from the DPB/WB database from 2008 to 2015 are transformed into grey numbers using

$$
\otimes x_{i j}=\left[\underline{x}_{i j}, \bar{x}_{i j}\right] \text {, }
$$

where

$$
\begin{aligned}
& \underline{x}_{i j}=\min \left(v_{i j}^{2008}, v_{i j}^{2009}, \ldots, v_{i j}^{2015}\right), \\
& \bar{x}_{i j}=\max \left(v_{i j}^{2008}, v_{i j}^{2009}, \ldots, v_{i j}^{2015}\right),
\end{aligned}
$$

where $v_{i j}$ is the value for the second-level criteria $j$ for country $i$ given by the DBP for the year 2008 to year 2015, $1 \leq$ $i \leq 19$, and $1 \leq j \leq 37$. To simplify the notation, we define $X_{i}=\left(\otimes x_{i, 1}, \otimes x_{i, 2}, \ldots, \otimes x_{i, 37}\right)$. For example, $X_{1}=$ $([7,10],[12,34],[55.8,198.1],[6.3,354.2],[9,13],[111,317]$, $[2.4,3.8],[0,5],[0,172],[0,14654.9],[4,4],[120,120]$, $[11.7,11.9],[3,6],[1,1],[7.8,10.9],[0,0],[6,7],[1,1]$, $[3,5],[55,55],[270,270],[0,15.9],[0,26.4],[0,21],[7,8]$, $[25,34],[987,1101],[7,9],[25,38],[1222,1569],[750,825]$, $[64.7,64.7],[41,42],[4,4],[14.5,21.5],[16.7,22.6])$. Other data are omitted here, and the complete data are provided by the DBP at http://www.doingbusiness.org/custom-query. The first element of the vector $X_{1}$ is $\otimes x_{1,1}$ and it corresponds to the number of Procedures in Starting a Business in the Republic of Benin with a lower bound of 7 and an upper bound of 10. All the elements of the vector $X_{i}$ have similar corresponding lower and upper bounds to the second-level criteria of every country.

Step 2 (normalize the grey decision matrix). A normalized grey decision matrix is constructed using (8).

For example, $X_{1}^{*}=([0.5333,0.7333],[0.8841,0.9705]$, $[0.8418,0.9638],[0.651,0.9938],[0.871,1],[0.5351,0.926]$, $[0.9846,0.9923],[0.4444,1],[0.706,1],[0.0416,1],[1,1]$, $[0.641,0.641],[0.4537,0.4634],[0.1429,0.5714],[0.1667$, $0.1667],[0.3391,0.4739],[0,0],[0,0.1667],[1,1],[0.4286$, $0.7143],[0.3158,0.3158],[0.8767,0.8767],[0.492,1],[0.2303$, $1],[0.9182,1],[0.6,0.8],[0.6667,0.803],[0.9317,0.951]$, $[0.5714,0.8571],[0.7273,0.875],[0.8937,0.9353],[0.6185$, 0.6706], [0.6473, 0.6473], [0.4118, 0.4706], [0.8, 0.8], [0.2417, $0.3583],[0.4441,0.6011])$. Other data are omitted here too.

Step 3 (determine the weights of the criteria). Grey linguistic values are used to estimate the weights of $7 \mathrm{DMs}$ based on the group aggregating technique used by some authors [2631]. The DMs are some Chinese investors that want to invest in Africa. A questionnaire in Chinese was designed to obtain the weights of the criteria. Grey linguistic values are used to measure the DMs' preferences in weights as shown in Table 2. The raw data can be found in [36].

Due to its simplicity of implementation, the grey arithmetic mean method is used to aggregate the weights $(W)$. The weights are scaled such that the summation of the upper bounds of the scaled grey weights is a unit value. After scaling using (11), we have

$$
\begin{aligned}
& W^{\prime}=([0.0144,0.0256],[0.0151,0.0265], \\
& {[0.0123,0.0229],[0.0123,0.0229],[0.0123,0.0229],} \\
& {[0.0129,0.0237],[0.0123,0.0229],[0.011,0.021],} \\
& {[0.0131,0.024],[0.0104,0.0203],[0.0158,0.0274],} \\
& {[0.0188,0.0313],[0.015,0.0264],[0.0201,0.0331],} \\
& {[0.018,0.0303],[0.0144,0.0256],[0.0144,0.0256],}
\end{aligned}
$$$$
[0.0219,0.0354],[0.0238,0.0377],[0.0219,0.0354] \text {, }
$$$$
[0.0144,0.0256],[0.0115,0.0218],[0.0165,0.0284] \text {, }
$$$$
[0.0172,0.0294],[0.0144,0.0256],[0.0123,0.0229] \text {, }
$$ 
TABLE 1: Hierarchy of the evaluation criteria.

\begin{tabular}{|c|c|c|c|}
\hline Goal & First-level criteria & Second-level criteria & Index $(k)$ \\
\hline \multirow{37}{*}{ Business Environment of Countries } & \multirow{4}{*}{ Starting a Business } & Procedures & 1 \\
\hline & & Time & 2 \\
\hline & & Cost & 3 \\
\hline & & Paid-in Minimum Capital & 4 \\
\hline & \multirow{3}{*}{ Dealing with Construction Permits } & Procedures & 5 \\
\hline & & Time & 6 \\
\hline & & Cost & 7 \\
\hline & \multirow{3}{*}{ Getting Electricity } & Procedures & 8 \\
\hline & & Time & 9 \\
\hline & & Cost & 10 \\
\hline & \multirow{3}{*}{ Registering Property } & Procedures & 11 \\
\hline & & Time & 12 \\
\hline & & Cost & 13 \\
\hline & \multirow{4}{*}{ Getting Credit } & Strength of Legal Rights Index & 14 \\
\hline & & Depth of Credit Information Index & 15 \\
\hline & & Credit Registry Coverage & 16 \\
\hline & & Credit Bureau Coverage & 17 \\
\hline & \multirow{3}{*}{ Protecting Minority Investors } & Extent of Disclosure Index & 18 \\
\hline & & Extent of Director Liability Index & 19 \\
\hline & & Ease of Shareholder Suits Index & 20 \\
\hline & \multirow{5}{*}{ Paying Taxes } & Payments & 21 \\
\hline & & Time & 22 \\
\hline & & Profit Tax & 23 \\
\hline & & Labour Tax and Contributions & 24 \\
\hline & & Other Taxes & 25 \\
\hline & \multirow{6}{*}{ Trading Across Borders } & Documents to Export & 26 \\
\hline & & Time to Export & 27 \\
\hline & & Cost to Export & 28 \\
\hline & & Documents to Import & 29 \\
\hline & & Time to Import & 30 \\
\hline & & Cost to Import & 31 \\
\hline & \multirow{3}{*}{ Enforcing Contracts } & Time & 32 \\
\hline & & Cost & 33 \\
\hline & & Procedures & 34 \\
\hline & \multirow{3}{*}{ Resolving Insolvency } & Time & 35 \\
\hline & & Cost & 36 \\
\hline & & Recovery Rate & 37 \\
\hline
\end{tabular}

TABLE 2: Grey linguistic values and their grey numbers.

\begin{tabular}{lc}
\hline Linguistic values & Grey weights \\
\hline Unimportant & {$[0,0.2]$} \\
Somewhat important & {$[0.2,0.4]$} \\
Moderately important & {$[0.4,0.6]$} \\
Important & {$[0.6,0.8]$} \\
Extremely important & {$[0.8,1]$} \\
\hline
\end{tabular}

$[0.0178,0.0302],[0.0185,0.0311],[0.0123,0.0229]$,

$[0.0171,0.0293],[0.0171,0.0293],[0.018,0.0303]$,

$[0.0171,0.0293],[0.018,0.0303],[0.0112,0.0212]$,

$[0.0137,0.0246],[0.0155,0.0272])^{T}$. 
Step 4 (aggregate the weighted grey decision matrix). The aggregated weights are calculated using (15):

$$
\begin{aligned}
Y= & \left(\otimes y_{1}, \otimes y_{2}, \otimes y_{3}, \otimes y_{4}, \otimes y_{5}, \otimes y_{6}, \otimes y_{7}, \otimes y_{8},\right. \\
& \otimes y_{9}, \otimes y_{10}, \otimes y_{11}, \otimes y_{12}, \otimes y_{13}, \otimes y_{14}, \otimes y_{15}, \otimes y_{16}, \\
& \left.\otimes y_{17}, \otimes y_{18}, \otimes y_{19}\right)^{T}, \\
Y= & ([0.3222,0.738],[0.2841,0.6751], \\
& {[0.3692,0.7732],[0.3045,0.6857],[0.2471,0.6091], } \\
& {[0.3204,0.7043],[0.3298,0.6677],[0.3757,0.7671], } \\
& {[0.3688,0.7927],[0.3307,0.6977],[0.2645,0.6564], } \\
& {[0.3211,0.6929],[0.6929,0.3142],[0.3249,0.6658], } \\
& {[0.31,0.6878],[0.2643,0.7138],[0.295,0.7349], } \\
& {[0.263,0.7164],[0.3232,0.7098])^{T} . }
\end{aligned}
$$

Step 5 (obtain the white values of the alternatives). From (19), where the center whitenization coefficient of $\lambda=0.5$ is taken, we have $V_{1}=0.5301, V_{2}=0.4796, V_{3}=0.5712, \ldots, V_{19}=$ 0.5165 . The results for Steps 5-7 are shown in Table 3.

Step 6 (determine the boundary distance of the alternatives). Using Manhattan distance for measuring the distance of (20), we have $S_{1}=0.4157, S_{2}=0.3910, S_{3}=0.4040, \ldots, S_{19}=$ 0.3866 .

Step 7 (rank the alternatives). The rank scores $z_{i}$ are calculated using (21): $z_{1}=0.3097, z_{2}=0.2921, z_{3}=0.3405, \ldots, z_{19}=$ 0.3168 . The percentage rank scores $Z_{i}$ are calculated using (22): $Z_{1}=89.06 \%, Z_{2}=84.00 \%, Z_{3}=97.91 \%, \ldots, Z_{19}=91.11 \%$.

Ranking these countries from the 1st position is as follows: the Gambia $>$ Cape Verde $>$ Ghana $>$ Equatorial Guinea $>$ Mauritania $>$ Guinea $>$ Liberia $>$ Togo $>$ Côte d'Ivoire $>$ Niger $>$ Benin $>$ Cameroon $>$ Mali $>$ Burkina Faso $>$ Senegal $>$ Guinea-Bissau $>$ Chad $>$ Nigeria $>$ Sierra Leone. Although Equatorial Guinea is ranked the 4 th position, it has the lowest degree of uncertainty for investment outcome with a value of 0.3379 . Sierra Leone, the least ranked country, has the highest degree of uncertainty with a value of 0.4533 as reflected by the boundary distance.

4.2. Comparison between DBP and GWSM Results. The DBP uses equal weights for the evaluation of business environment. Equal weights may be regarded as an acceptable representation of the criteria weights when the weights are unknown. Nevertheless, there is little or no disadvantage in measuring the weights of investors who intend to invest in West Africa. The investors can be regarded as the DMs. Table 4 shows the cumulative performances and rankings of West African countries based on the evaluation method of the DBP from the year 2008 to 2015 [77]. The DBP rankings for the year 2008 to 2015 are compared with the GWSM from the year 2008 to 2015. Figure 1 shows a clustered bar graph with the results of these two methods where the rankings of the cumulative DBP, GWSM using grey weights, and GWSM
TABLE 3: GWSM rankings for the year 2008 to the year 2015.

\begin{tabular}{lcccccc}
\hline Index $(i)$ & Countries & $V$ & $S$ & $z$ & $Z(\%)$ & Rankings \\
\hline 1 & Benin & 0.5301 & 0.4157 & 0.3097 & 89.06 & 11 \\
2 & Burkina & 0.4796 & 0.3910 & 0.2921 & 84 & 14 \\
3 & Faso & & & & & \\
4 & Cameroon & 0.4951 & 0.3812 & 0.3063 & 88.09 & 12 \\
5 & Cape Verde & 0.5712 & 0.4040 & 0.3405 & 97.91 & 2 \\
6 & Chad & 0.4281 & 0.3620 & 0.2731 & 78.54 & 17 \\
6 & Côte & 0.5124 & 0.3839 & 0.3157 & 90.77 & 9 \\
7 & d'Ivoire & & & & & \\
8 & Equatorial & 0.4987 & 0.3379 & 0.3302 & 94.95 & 4 \\
9 & Guinea & & & & & \\
10 & The Gambia & 0.5714 & 0.3914 & 0.3477 & 100 & 1 \\
11 & Ghana & 0.5808 & 0.4239 & 0.3346 & 96.22 & 3 \\
12 & Guinea & 0.5142 & 0.3669 & 0.3255 & 93.61 & 6 \\
13 & Guinea- & 0.4604 & 0.3920 & 0.28 & 80.51 & 16 \\
14 & Bissau & & & & & \\
15 & Liberia & 0.507 & 0.3718 & 0.3185 & 91.59 & 7 \\
16 & Mali & 0.5245 & 0.4206 & 0.3039 & 87.38 & 13 \\
17 & Mauritania & 0.4953 & 0.3409 & 0.3265 & 93.88 & 5 \\
\hline & Niger & 0.4989 & 0.3778 & 0.3104 & 89.26 & 10 \\
& Nigeria & 0.489 & 0.4495 & 0.2692 & 77.41 & 18 \\
& Senegal & 0.515 & 0.4400 & 0.2884 & 82.93 & 15 \\
& Togo & 0.5165 & 0.3866 & 0.3168 & 91.11 & 8 \\
\hline & & & & & &
\end{tabular}

using equal weights are represented as white, solid black, and checkerboard fillings, respectively.

Firstly, we compare the GWSM using grey weights with DBP method. The ranking for each country changes using both methods except Cape Verde. The Gambia is ranked the 1st position using the GWSM and Ghana is the 1st position using the cumulative result of the DBP. However, Ghana is ranked the $3 \mathrm{rd}$ position. The ranking of Cape Verde, the $2 \mathrm{nd}$ position, is unchanged using both methods. The Gambia is ranked the 3rd position using the cumulative DBP method. Although Sierra Leone is ranked the 4 th position by the DBP method, the GWSM ranks Sierra Leone the 19th position because of the highest degree of uncertainty with a value of 0.4533 measured as the aggregated boundary distances. Sierra Leone has some very poor performance in some criteria; for instance, the cost of starting a business, the number of procedures in getting electricity, and the cost of enforcing contracts have grey values of $[38,1180.7],[0,9]$, and $[40$, 149.5], respectively. In comparison to the Gambia, these grey values are $[131,279],[0,5]$, and $[46,46]$. Similarly, Nigeria is ranked the 18th position using the GWSM which has a degree of uncertainty of 0.4533 . A corresponding moderate degree of uncertainty in Togo's business environment (0.3866) has improved its ranking from the 16th position using the cumulative DBP method to the 8th position using the GWSM.

Secondly, we make a comparison of both methods using equal weights. We acknowledge the importance of weights in 
TABLE 4: DBP rankings for the year 2008 to the year 2015.

\begin{tabular}{lcccccccccc}
\hline Countries/years & 2008 & 2009 & 2010 & 2011 & 2012 & 2013 & 2014 & 2015 & Total & Rankings \\
\hline Benin & 39.18 & 37.64 & 38.67 & 40.21 & 42.75 & 44.37 & 46.61 & 51.1 & 340.53 & 14 \\
Burkina Faso & 32.49 & 37.31 & 41.01 & 42.28 & 45.58 & 45.87 & 47.89 & 48.36 & 340.79 & 13 \\
Cameroon & 39.71 & 39.24 & 43.33 & 45.38 & 47.75 & 48.79 & 50.35 & 49.85 & 364.4 & 7 \\
Cape Verde & 50.73 & 51.04 & 53.32 & 55.82 & 58.58 & 58.85 & 58.03 & 57.94 & 444.3 & 2 \\
Chad & 28.32 & 28.67 & 30.1 & 29.72 & 32.39 & 32.56 & 35.57 & 37.25 & 254.58 & 19 \\
Côte d'Ivoire & 40.13 & 40.27 & 41.36 & 41.5 & 44.18 & 44.83 & 48.9 & 52.26 & 353.43 \\
Equatorial Guinea & 42.26 & 42.25 & 45.78 & 45.09 & 47.55 & 47.89 & 47.74 & 49.01 & 367.58 \\
The Gambia & 48.44 & 48.62 & 48.47 & 48.77 & 49.9 & 51.6 & 51.76 & 54.81 & 402.36 \\
Ghana & 59.43 & 60.7 & 61.47 & 63.61 & 64.28 & 67.78 & 64.41 & 65.24 & 506.92 \\
Guinea & 35.75 & 35.89 & 37.23 & 35.97 & 38.59 & 41.48 & 46.54 & 47.42 & 318.87 & 3 \\
Guinea-Bissau & 32.6 & 32.37 & 33.46 & 33.62 & 40.98 & 42.12 & 43.55 & 43.21 & 301.9 & 17 \\
Liberia & 37.54 & 41.23 & 42.2 & 42.28 & 46.47 & 48.53 & 46.56 & 46.61 & 351.42 \\
Mali & 36.73 & 38.32 & 44.3 & 47.46 & 49.03 & 50.24 & 52.06 & 52.59 & 370.73 \\
Mauritania & 39.33 & 40.98 & 41.42 & 42.52 & 44.91 & 45.02 & 44.69 & 44.21 & 343.08 & 18 \\
Niger & 37.43 & 37.4 & 38.89 & 39.95 & 43.27 & 44.96 & 46.91 & 47.63 & 336.43 \\
Nigeria & 44.46 & 44.16 & 42.83 & 42.65 & 43.93 & 43.7 & 43.72 & 47.33 & 352.78 & 12 \\
Senegal & 36.79 & 42.48 & 41.89 & 42.08 & 43.94 & 44.27 & 46.09 & 49.37 & 346.91 & 9 \\
Sierra Leone & 35.45 & 42.53 & 39.87 & 44.31 & 48.39 & 49.18 & 52.78 & 54.58 & 367.09 & 6 \\
Togo & 35.6 & 35.73 & 38.58 & 39.27 & 41.62 & 43.61 & 47.03 & 51.29 & 332.73 & 16 \\
\hline
\end{tabular}

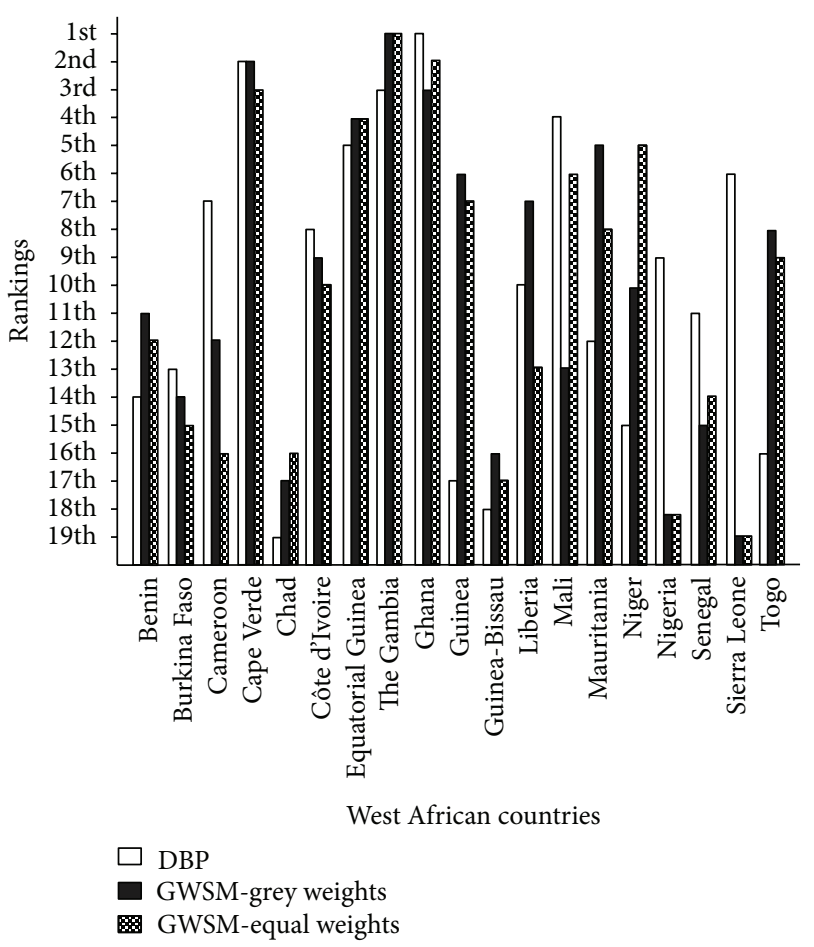

FIGURE 1: Rankings comparison between the DBP and the GWSM.

decision-making. The DBP uses equal weights for the evaluation of business environment. For a balanced comparison between the DBP method and GWSM, we also present the GWSM using equal weight. Equal weights are real numbers.
Following the GWSM steps using equals weights for all the first-level criteria and their second-level criteria, we have

$$
\begin{aligned}
& W^{\prime}=(0.025,0.025,0.025,0.025,0.0333,0.0333, \\
& 0.0333,0.0333,0.0333,0.0333,0.0333,0.0333 \text {, } \\
& 0.0333,0.025,0.025,0.025,0.025,0.0333 \text {, } \\
& 0.0333,0.0333,0.02,0.02,0.02,0.02,0.02 \text {, } \\
& \text { 0.0167, 0.0167, 0.0167, 0.0167, 0.0167, 0.0167, } \\
& 0.0333,0.0333,0.0333,0.0333,0.0333 \text {, } \\
& 0.0333)^{T} \text {. }
\end{aligned}
$$

The ranking of West African countries from the 1st position is as follows: the Gambia > Ghana $>$ Cape Verde $>$ Equatorial Guinea $>$ Niger $>$ Mali $>$ Guinea $>$ Mauritania $>$ Togo $>$ Côte d'Ivoire $>$ Cameroon $>$ Benin $>$ Liberia $>$ Senegal $>$ Burkina Faso $>$ Chad $>$ Guinea-Bissau $>$ Nigeria $>$ Sierra Leone. Based on equal weights, the Gambia is still ranked the 1st position using the GWSM, and Ghana is the 1st using the cumulative result of the DBP. But after considering uncertainty over the period of the year 2008 to 2015, Ghana is ranked the 2nd position with Cape Verde the 2nd position using DBP method. Also, Cape Verde is a rank lower, the 3rd position, using the GWSM, and the Gambia is then ranked the 3rd position using the DBP method. Chad, which is ranked the 19th position using the DBP method, is ranked the 16th position using GWSM. Although Sierra Leone is ranked the 4 th position by the DBP, GWSM ranks Sierra Leone the 19th position because of the highest degree of uncertainty with a value of 0.2814 
measured as the aggregated boundary distances. The degree of uncertainty of Sierra Leone is more than twice that of the Gambia that has a value of 0.1093. Likewise, Nigeria is ranked the 18th position using the GWSM which has a degree of uncertainty of 0.2633 . A corresponding moderate degree of uncertainty of Guinea and Niger has improved it ranking from the 17 th position and the 15 th position using the cumulative DBP method to the 7 th position and the 5 th position, respectively.

Lastly, we compare equal weights and grey weights using the GWSM. Liberia, Mali, and Niger are majorly affected by our investor's preferences. Mali that is ranked the 6th position using equal weights becomes the 13th position using grey weights, and Liberia that is the 13th position using equal weights becomes the 7 th position using grey weights. The ranking of Niger from the 5th position using equal weights becomes 10th position using grey weights. The weights of the DMs did not affect the rankings of the Gambia, Equatorial Guinea, Nigeria, and Sierra Leone as the 1st, 4th, 18th, and 19th positions, respectively. The outcome of making a longterm investment in countries with lower uncertainty values is highly predictable. It is not unusual for different ranking methods to produce different rankings most especially under different conditions [78]. The degree of uncertainty, the boundary distance, plays a significant role in ranking the Gambia as the 1st country. Also, uncertainty and the weights of the criteria are the two factors for the difference in rankings using the DBP and GWSM methods.

\section{Sensitivity Analysis}

Sensitivity analysis is performed to show the robustness and the degree of uncertainty covered by the GWSM results. Through the sensitivity analysis, ranges of values for the input parameters and coefficients that do not affect the rankings can be obtained.

5.1. Whitenization Sensitivity. The white value is dependent on the whitenization coefficient $(\lambda)$. The whitenization coefficient helps to determine the minimum and maximum overall performances of the countries. The whitenization coefficient changes with an increment of 0.2 while keeping other input parameters unchanged. The results of the whitenization sensitivity when $\lambda=0,0.2,0.4,0.6,0.8,1$ are given in Table 5, showing the effect of a change in $\lambda$ on the rankings. Cape Verde, Côte d'Ivoire, the Gambia, and Guinea-Bissau are unaffected by the changes in whitenization coefficient. As $\lambda$ increases, the rankings for Cameroon and Chad rankings become better, while the rankings for Benin, Ghana, and Mauritania become worse.

5.2. Period Sensitivity. Interval grey numbers are used to represent the values of the criteria from the year 2008 to the year 2015, a period of 8 years. However, the effects of representing a period of 6 years (2010-2015) and a period of 3 years (2012-2015) with grey numbers are shown in Table 6. The Gambia is ranked the 1st position over a long period (2008-2015), Ghana is ranked the 2nd position, and Cape Verde is ranked the 3 rd position. However, for a short period
TABLE 5: Whitenization sensitivity on rankings.

\begin{tabular}{lcccccc}
\hline Countries/ $\lambda$ & 0 & 0.2 & 0.4 & 0.6 & 0.8 & 1 \\
\hline Benin & 10 & 10 & 10 & 11 & 11 & 12 \\
Burkina Faso & 15 & 14 & 14 & 14 & 14 & 14 \\
Cameroon & 13 & 12 & 12 & 12 & 12 & 11 \\
Cape Verde & 2 & 2 & 2 & 2 & 2 & 2 \\
Chad & 19 & 18 & 17 & 17 & 17 & 17 \\
Côte d'Ivoire & 9 & 9 & 9 & 9 & 9 & 9 \\
Equatorial Guinea & 4 & 4 & 4 & 4 & 3 & 3 \\
The Gambia & 1 & 1 & 1 & 1 & 1 & 1 \\
Ghana & 3 & 3 & 3 & 3 & 4 & 5 \\
Guinea & 5 & 5 & 6 & 6 & 6 & 6 \\
Guinea-Bissau & 16 & 16 & 16 & 16 & 16 & 16 \\
Liberia & 8 & 7 & 7 & 7 & 7 & 7 \\
Mali & 12 & 13 & 13 & 13 & 13 & 13 \\
Mauritania & 6 & 6 & 5 & 5 & 5 & 4 \\
Niger & 11 & 11 & 11 & 10 & 10 & 10 \\
Nigeria & 17 & 17 & 18 & 18 & 18 & 18 \\
Senegal & 14 & 15 & 15 & 15 & 15 & 15 \\
Sierra Leone & 18 & 19 & 19 & 19 & 19 & 19 \\
Togo & 7 & 8 & 8 & 8 & 8 & 8 \\
\hline
\end{tabular}

(2010-2015 and 2012-2015), Cape Verde is ranked the 1st position and the Gambia is ranked the 2 nd position. Ghana is ranked the 3rd position for the preriod of 2010 to 2015 while Mali is ranked the 3rd position for the period of 2012 to 2015. Burkina Faso made a very significant change from the 15th position in the period of the year 2008 to 2015 and the 10th in the period of 2010-2015 to the 7 th position in a shorter period (2012-2015). Niger moves from the 5th position in 2008-2015 to the 13th position in the year 2010 to 2015 and then 16th position in 2012-2015.

5.3. Distance Sensitivity. The distance measurement of the lower and upper bounds of grey number has a direct impact on the degree of uncertainty. Using different distance measurement values of $p$ in (20), the effects of distance measurement considering the Manhattan $(p=1)$, Euclidian $(p=2)$, and Minkowski $(p=3)$ distances on the ranking are obtained and shown in Table 7. From Table 7, it is evident that the distances measurement has an influence on the assessment of decision alternatives because as $p$ trends to infinity, the boundary distance approaches the upper bound of the weighted aggregated sum of the criteria as shown in (28). For $\bar{y}_{i}>\underline{y}_{i}$,

$$
S_{i}=\sqrt[p]{\left(\bar{y}_{i}\right)^{p}-\left(\underline{y}_{i}\right)^{p}} \underset{p \rightarrow \infty}{=} \bar{y}_{i} .
$$

The Manhattan distance measurement reflects the true degree of uncertainty in the business environment. However, using the Euclidian and the Minkowski $(p=3)$ distances, Equatorial Guinea and Mauritania are ranked the 1st and 2nd positions, respectively. When $p=2$, Guinea-Bissau is ranked the 3rd position using Euclidian distance, while Chad is ranked the 3rd when $p=3$. 
TABLE 6: Period sensitivity on rankings.

\begin{tabular}{lccc}
\hline Countries/period & $2008-2015$ & $2010-2015$ & $2012-2015$ \\
\hline Benin & 12 & 12 & 12 \\
Burkina Faso & 15 & 10 & 7 \\
Cameroon & 11 & 15 & 11 \\
Cape Verde & 3 & 1 & 1 \\
Chad & 16 & 19 & 19 \\
Côte d'Ivoire & 10 & 14 & 15 \\
Equatorial Guinea & 4 & 5 & 6 \\
The Gambia & 1 & 2 & 2 \\
Ghana & 2 & 3 & 9 \\
Guinea & 7 & 9 & 10 \\
Guinea-Bissau & 17 & 17 & 17 \\
Liberia & 13 & 4 & 4 \\
Mali & 6 & 7 & 3 \\
Mauritania & 8 & 6 & 5 \\
Niger & 5 & 13 & 16 \\
Nigeria & 18 & 18 & 18 \\
Senegal & 14 & 8 & 8 \\
Sierra Leone & 19 & 16 & 13 \\
Togo & 9 & 11 & 14 \\
\hline
\end{tabular}

TABLE 7: Distance measurement sensitivity on rankings.

\begin{tabular}{lccc}
\hline Countries/distance & $\begin{array}{c}\text { Manhattan } \\
(p=1)\end{array}$ & $\begin{array}{c}\text { Euclidian } \\
(p=2)\end{array}$ & $\begin{array}{c}\text { Minkowski } \\
(p=3)\end{array}$ \\
\hline Benin & 11 & 14 & 13 \\
Burkina Faso & 14 & 11 & 9 \\
Cameroon & 12 & 7 & 7 \\
Cape Verde & 2 & 13 & 15 \\
Chad & 17 & 9 & 3 \\
Côte d'Ivoire & 9 & 6 & 10 \\
Equatorial Guinea & 4 & 1 & 1 \\
The Gambia & 1 & 10 & 12 \\
Ghana & 3 & 16 & 19 \\
Guinea & 6 & 3 & 4 \\
Guinea-Bissau & 16 & 12 & 8 \\
Liberia & 7 & 4 & 5 \\
Mali & 13 & 15 & 14 \\
Mauritania & 5 & 2 & 2 \\
Niger & 10 & 5 & 6 \\
Nigeria & 18 & 18 & 16 \\
Senegal & 15 & 17 & 17 \\
Sierra Leone & 19 & 19 & 18 \\
Togo & 8 & 8 & \\
\hline
\end{tabular}

\section{Conclusion}

All investors have their methods and criteria for deciding which country to invest. The World Bank has done a great work by providing the annual data on country's performances to help investors and researchers. However, care should be taken in making use of these data because the DBP approach cannot provide an evaluation over a period of years. In this regard, we have assessed the performances of the West African countries using a new method called GWSM. In evaluating the business environment, values of the criteria for all the alternatives are transformed to grey numbers based on their performances over the period of the year 2008 to the year 2015. A decision matrix is constructed and normalized, and then the weighted grey decision matrix is obtained, and uncertainties are considered in the evaluation. The main contribution of this paper is that GWSM can evaluate alternatives over a period of years, and it can open new possibilities for multiple hybrid evaluation methods.

The ranking provided by the DBP presents a generalised ranking by using equal weights of the criteria in evaluating these countries. It is almost impossible for an investor to have an equal preference for all measurable criteria, that is, all criteria having equal weights. Grey weights of the criteria are obtained from investors measured as grey linguistic values. The GWSM provides a better evaluation result over a period of 8 years. The results obtained from the research ranked the Gambia as the 1st position in West Africa based on the degree of uncertainty. Cape Verde and Ghana are highly recommended. There should be deeper thought investing in Sierra Leone and Nigeria. Be sure these countries are in your line of business; for example, Nigeria is the oil giant in West Africa producing over 2.5 million barrels of crude oil per day [79].

Future studies on reducing the numbers of criteria and further work on evaluating the DM's weights can be done because not all experts should be rated equally. Since some DMs have longer years of experiences and some have worked in different countries, all these account for their preferences. The GWSM is a framework for decision-making under uncertain decision environment. Other hybrid methods can be derived when GWSM is combined with existing MCDM weighing techniques, which may provide new methods to evaluate alternatives under uncertain decision-making environment.

\section{Competing Interests}

The authors declare that they have no competing interests.

\section{References}

[1] M. Blowfield, "Business and development: making sense of business as a development agent," Corporate Governance, vol. 12, no. 4, pp. 414-426, 2012.

[2] K. Chelst and Y. B. Canbolat, Value-Added Decision Making for Managers, CRC Press, New York, NY, USA, 2011.

[3] D. R. Karanki, Uncertainty Management in Reliability Assessment, Lambert Academic Publishing, 2010.

[4] The World Bank, "About Doing Business: Measuring for impact," 2014, http://elibrary.worldbank.org/doi/abs/10.1596/ 978-0-8213-9984-2_About_Doing_Business.

[5] G.-H. Tzeng and J.-J. Huang, Multiple Attribute Decision Making: Methods and Applications, CRC Press, Boca Raton, Fla, USA, 2011 . 
[6] E. K. Zavadskas, Z. Turskis, and S. Kildiene, "State of art surveys of overviews on MCDM/MADM methods," Technological and Economic Development of Economy, vol. 20, no. 1, pp. 165-179, 2014.

[7] D. Jato-Espino, E. Castillo-Lopez, J. Rodriguez-Hernandez, and J. C. Canteras-Jordana, "A review of application of multicriteria decision making methods in construction," Automation in Construction, vol. 45, pp. 151-162, 2014.

[8] T. L. Saaty, "Decision making with the analytic hierarchy process," International Journal of Services Sciences, vol. 1, no. 1, p. 83, 2008.

[9] T. L. Saaty, "Decision making-the Analytic Hierarchy and Network Processes (AHP/ANP)," Journal of Systems Science and Systems Engineering, vol. 13, no. 1, pp. 1-35, 2004.

[10] J. Antucheviciene, A. Zakarevicius, and E. K. Zavadskas, "Measuring congruence of ranking results applying particular MCDM methods," Informatica, vol. 22, no. 3, pp. 319-338, 2011.

[11] E. K. Zavadskas and A. Kaklauskas, Systemic-Technical Assessment of Buildings, Technika, Vilnius, Lithuania, 1996.

[12] H. G. Shakouri, M. Nabaee, and S. Aliakbarisani, "A quantitative discussion on the assessment of power supply technologies: DEA (data envelopment analysis) and SAW (simple additive weighting) as complementary methods for the "Grammar," Energy, vol. 64, pp. 640-647, 2014.

[13] B. Roy, "Classement et choix en présence de points de vue multiples," RAIRO—Recherche Opérationnelle, vol. 2, no. V1, pp. 57-75, 1968.

[14] L. A. D. Rangel, L. F. A. M. Gomes, and R. A. Moreira, "Decision theory with multiple criteria: an application of ELECTRE IV and TODIM to SEBRAE/RJ," Pesquisa Operacional, vol. 29, no. 3, pp. 577-590, 2009.

[15] C. L. Hwang and K. Yoon, Multiple Attribute Decision Making, Springer, Berlin, Germany, 1981.

[16] G. Qian and X. Qian, "The evidential reasoning approach for multiple attribute decision analysis using intuitionistic fuzzy information," in Proceedings of the 4th International Conference on Wireless Communications, Networking and Mobile Computing (WiCOM '08), pp. 1-5, Dalian, China, October 2008.

[17] G. Shafer, A mathematical theory of evidence, Princeton University Press, Princeton, NJ, USA, 1976.

[18] C. Hamzaçebi and M. Pekkaya, "Determining of stock investments with grey relational analysis," Expert Systems with Applications, vol. 38, no. 8, pp. 9186-9195, 2011.

[19] J. Wallenius, J. S. Dyer, P. C. Fishburn, R. E. Steuer, S. Zionts, and K. Deb, "Multiple criteria decision making, multiattribute utility theory: recent accomplishments and what lies ahead," Management Science, vol. 54, no. 7, pp. 1336-1349, 2008.

[20] M. Behzadian, R. B. Kazemzadeh, A. Albadvi, and M. Aghdasi, "PROMETHEE: a comprehensive literature review on methodologies and applications," European Journal of Operational Research, vol. 200, no. 1, pp. 198-215, 2010.

[21] X. Xu, "The SIR method: a superiority and inferiority ranking method for multiple criteria decision making," European Journal of Operational Research, vol. 131, no. 3, pp. 587-602, 2001.

[22] W. Edwards and F. H. Barron, "SMARTS and SMARTER: improved simple methods for multiattribute utility measurement," Organizational Behavior and Human Decision Processes, vol. 60, no. 3, pp. 306-325, 1994.

[23] F. H. Barron and B. E. Barrett, "The efficacy of SMARTERsimple multi-attribute rating technique extended to ranking," Acta Psychologica, vol. 93, no. 1-3, pp. 23-36, 1996.
[24] J.-J. Wang, Y.-Y. Jing, C.-F. Zhang, and J.-H. Zhao, "Review on multi-criteria decision analysis aid in sustainable energy decision-making," Renewable and Sustainable Energy Reviews, vol. 13, no. 9, pp. 2263-2278, 2009.

[25] L. A. Zadeh, "The concept of a linguistic variable and its application to approximate reasoning-I," Information Sciences, vol. 8, no. 3, pp. 199-249, 1975.

[26] G.-D. Li, D. Yamaguchi, and M. Nagai, "A grey-based rough decision-making approach to supplier selection," The International Journal of Advanced Manufacturing Technology, vol. 36, no. 9-10, pp. 1032-1040, 2008.

[27] D. Wang, "Extension of TOPSIS method for R\&D personnel selection problem with interval grey number," in Proceedings of the International Conference on Management and Service Science (MASS '09), pp. 1-4, Wuhan, China, September 2009.

[28] C. Bai and J. Sarkis, "A grey-based DEMATEL model for evaluating business process management critical success factors," International Journal of Production Economics, vol. 146, no. 1, pp. 281-292, 2013.

[29] E. Kose, M. Kabak, and H. Aplak, "Grey theory based MCDM procedure for sniper selection problem," Grey Systems: Theory and Application, vol. 3, no. 1, pp. 35-45, 2013.

[30] H. Kuang, K. W. Hipel, and D. M. Kilgour, "Evaluation of source water protection strategies in Waterloo Region based on Grey Systems Theory and PROMETHEE II," in Proceedings of the IEEE International Conference on Systems, Man, and Cybernetics (SMC '12), pp. 2775-2779, IEEE, Seoul, Republic of Korea, October 2012.

[31] Y. Z. Mehrjerdi, "Strategic system selection with linguistic preferences and grey information using MCDM," Applied Soft Computing, vol. 18, pp. 323-337, 2014.

[32] H. K. Kang, D. G. Kim, H. W. Jeong, G. Y. Park, and H. Y. Youn, "A novel interval grey number and entropy-based solution for multiple-criteria group decision making problem," in Proceedings of the 9th International Conference on Ubiquitous Intelligence Computing and 9th International Conference on Autonomic Trusted Computing (UIC/ATC '12), pp. 349-356, September 2012.

[33] Z.-J. Ma, N. Zhang, and Y. Dai, "Some induced correlated aggregating operators with interval grey uncertain linguistic information and their application to multiple attribute group decision making," Mathematical Problems in Engineering, vol. 2013, Article ID 160610, 11 pages, 2013.

[34] N. Zhang, "Method for aggregating correlated interval grey linguistic variables and its application to decision making," Technological and Economic Development of Economy, vol. 19, no. 2, pp. 189-202, 2013.

[35] F. Jin, P. Liu, and X. Zhang, “The multi-attribute group decision making method based on the interval grey linguistic variables weighted harmonic aggregation operators," Technological and Economic Development of Economy, vol. 19, no. 3, pp. 409-430, 2013.

[36] M. O. Esangbedo and A. Che, "Evaluating business environment in Africa using grey number weights," Journal of Grey System, vol. 28, no. 3, pp. 26-47, 2016.

[37] A. Afshari, M. Mojahed, and R. M. Yusuff, "Simple additive weighting approach to personnel selection problem," International Journal of Innovation, Management and Technology, vol. 1, no. 5, pp. 511-515, 2010.

[38] A. Memariani, A. Amini, and A. Alinezhad, "Sensitivity analysis of simple additive weighting method (SAW): the results of 
change in the weight of one attribute on the final ranking of alternatives," Journal of Industrial Engineering, vol. 4, pp. 13-18, 2009.

[39] M. N. Andalecio, "Multi-criteria decision models for management of tropical coastal fisheries. A review," Agronomy for Sustainable Development, vol. 30, no. 3, pp. 557-580, 2010.

[40] S.-Y. Chou, Y.-H. Chang, and C.-Y. Shen, "A fuzzy simple additive weighting system under group decision-making for facility location selection with objective/subjective attributes," European Journal of Operational Research, vol. 189, no. 1, pp. 132-145, 2008.

[41] K. R. MacCrimmon, Decisionmaking among Multiple-Attribute Alternatives: A Survey and Consolidated Approach, Advanced Research Projects Agency, 1968.

[42] E. Triantaphyllou and S. H. Mann, "An examination of the effectiveness of multi-dimensional decision-making methods: a decision-making paradox," Decision Support Systems, vol. 5, no. 3, pp. 303-312, 1989.

[43] L. Abdullah and C. R. Adawiyah, "Simple additive weighting methods of multi criteria decision making and applications: a decade review," International Journal of Information Processing and Management, vol. 5, no. 1, p. 39, 2014.

[44] C.-H. Goh, Y.-C. A. Tung, and C.-H. Cheng, "A revised weighted sum decision model for robot selection," Computers \& Industrial Engineering, vol. 30, no. 2, pp. 193-199, 1996.

[45] E. Triantaphyllou and C.-T. Lin, "Development and evaluation of five fuzzy multiattribute decision-making methods," International Journal of Approximate Reasoning, vol. 14, no. 4, pp. 281310, 1996.

[46] M. Modarres and S. Sadi-Nezhad, "Fuzzy simple additive weighting method by preference ratio," Intelligent AutomationSoft Computing, vol. 11, no. 4, pp. 235-244, 2005.

[47] E. K. Zavadskas, Z. Turskis, J. Antucheviciene, and A. Zakarevicius, "Optimization of weighted aggregated sum product assessment," Elektronika ir Elektrotechnika, vol. 122, no. 6, pp. 3-6, 2012.

[48] E. K. Zavadskas, J. Antucheviciene, S. H. Razavi Hajiagha, and S. S. Hashemi, "Extension of weighted aggregated sum product assessment with interval-valued intuitionistic fuzzy numbers (WASPAS-IVIF)," Applied Soft Computing Journal, vol. 24, pp. 1013-1021, 2014.

[49] E. K. Zavadskas, Z. Turskis, and J. Antuceviciene, "Selecting a contractor by using a novel method for multiple attribute analysis: weighted aggregated sum product assessment with grey values (WASPAS-G)," Studies in Informatics and Control, vol. 24, no. 2, pp. 141-150, 2015.

[50] D. Stanujkic and E. K. Zavadskas, "A modified weighted sum method based on the decision-maker's preferred levels of performances," Studies in Informatics and Control, vol. 24, no. 4, pp. 461-469, 2015.

[51] T.-Y. Chen, "An interactive signed distance approach for multiple criteria group decision-making based on simple additive weighting method with incomplete preference information defined by interval type-2 fuzzy sets," International Journal of Information Technology and Decision Making, vol. 13, no. 5, pp. 979-1012, 2014.

[52] Y.-J. Wang, "A fuzzy multi-criteria decision-making model based on simple additive weighting method and relative preference relation," Applied Soft Computing Journal, vol. 30, pp. 412420, 2015.

[53] N. Zamri and L. Abdullah, "A linear assignment method of simple additive weighting system in linear programming approach under interval type-2 fuzzy set concepts for MCDM problem," in Advanced Computer and Communication Engineering Technology, H. A. Sulaiman, M. A. Othman, M. F. I. Othman, Y. A. Rahim, and N. C. Pee, Eds., pp. 833-842, Springer International, Berlin, Germany, 2015.

[54] Y. Xu, W. Zhang, and H. Wang, "A conflict-eliminating approach for emergency group decision of unconventional incidents," Knowledge-Based Systems, vol. 83, no. 1, pp. 92-104, 2015.

[55] J.-L. Deng, “Control problems of grey systems," Systems \& Control Letters, vol. 1, no. 5, pp. 288-294, 1982.

[56] M.-S. Yin, "Fifteen years of grey system theory research: a historical review and bibliometric analysis," Expert Systems with Applications, vol. 40, no. 7, pp. 2767-2775, 2013.

[57] P. Delcea Camelia and D. Camelia, "Grey systems theory in economics-a historical applications review," Grey Systems: Theory and Application, vol. 5, no. 2, pp. 263-276, 2015.

[58] J. Xu and M. Sasaki, "Technique of order preference by similarity for multiple attribute decision making based on grey members," IEEJ Transactions on Electronics, Information and Systems, vol. 124, no. 10, pp. 1999-2005, 2004.

[59] G.-D. Li, D. Yamaguchi, and M. Nagai, "A grey-based decisionmaking approach to the supplier selection problem," Mathematical and Computer Modelling, vol. 46, no. 3-4, pp. 573-581, 2007.

[60] Z. Turskis and E. K. Zavadskas, "A novel method for multiple criteria analysis: grey additive ratio assessment (ARAS-G) method," Informatica, vol. 21, no. 4, pp. 597-610, 2010.

[61] L. Liu, J.-H. Chen, G.-M. Wang, and D.-Z. Lao, "Multiattributed decision making for mining methods based on grey system and interval numbers," Journal of Central South University, vol. 20, no. 4, pp. 1029-1033, 2013.

[62] S. M. Mousavi, B. Vahdani, R. Tavakkoli-Moghaddam, and N. Tajik, "Soft computing based on a fuzzy grey group compromise solution approach with an application to the selection problem of material handling equipment," International Journal of Computer Integrated Manufacturing, vol. 27, no. 6, pp. 547-569, 2014.

[63] B. Oztaysi, "A decision model for information technology selection using AHP integrated TOPSIS-Grey: the case of content management systems," Knowledge-Based Systems, vol. 70, pp. 44-54, 2014.

[64] E. K. Zavadskas, T. Vilutiene, Z. Turskis, and J. Tamosaitiene, "Contractor selection for construction works by applying saw-g and topsis grey techniques," Journal of Business Economics and Management, vol. 11, no. 1, pp. 34-55, 2010.

[65] S. H. Zolfani, M. Sedaghat, and E. K. Zavadskas, "Performance evaluating of rural ICT centers (telecenters), applying fuzzy AHP, SAW-G and TOPSIS Grey, a case study in Iran," Technological and Economic Development of Economy, vol. 18, no. 2, pp. 364-387, 2012.

[66] S. Datta, N. Sahu, and S. Mahapatra, "Robot selection based on grey-MULTIMOORA approach," Grey Systems: Theory and Application, vol. 3, no. 2, pp. 201-232, 2013.

[67] Q. Li and N. Zhao, "Stochastic interval-grey number VIKOR method based on prospect theory," Grey Systems: Theory and Application, vol. 5, no. 1, pp. 105-116, 2015.

[68] S. Liu and Y. Lin, Grey Information: Theory and Practical Applications, Springer, 2005.

[69] S. Liu and Y. Lin, "Introduction to grey systems theory," in Grey Systems, chapter 1, Springer, New York, NY, USA, 2011.

[70] T. Aven and E. Zio, "Some considerations on the treatment of uncertainties in risk assessment for practical decision making," 
Reliability Engineering and System Safety, vol. 96, no. 1, pp. 6474, 2011.

[71] Y.-H. Lin, P.-C. Lee, and H.-I. Ting, "Dynamic multi-attribute decision making model with grey number evaluations," Expert Systems with Applications, vol. 35, no. 4, pp. 1638-1644, 2008.

[72] G. R. Pophali, A. B. Chelani, and R. S. Dhodapkar, "Optimal selection of full scale tannery effluent treatment alternative using integrated AHP and GRA approach," Expert Systems with Applications, vol. 38, no. 9, pp. 10889-10895, 2011.

[73] M. Kabak, S. Burmaoğlu, and Y. Kazançoğlu, "A fuzzy hybrid MCDM approach for professional selection," Expert Systems with Applications, vol. 39, no. 3, pp. 3516-3525, 2012.

[74] Y. Beikkhakhian, M. Javanmardi, M. Karbasian, and B. Khayambashi, "The application of ISM model in evaluating agile suppliers selection criteria and ranking suppliers using fuzzy TOPSIS-AHP methods," Expert Systems with Applications, vol. 42, no. 15-16, pp. 6224-6236, 2015.

[75] J. D. Fage, "Western Africa-region, Africa," http://global .britannica.com/EBchecked/topic/640491/western-Africa.

[76] Doing Business, "Doing Business 2015 Going Beyond Efficiency," 2014.

[77] Doing Business, "Historical Data Sets and Trends," World Bank Group, http://www.doingbusiness.org/custom-query.

[78] K. J. Arrow, "A difficulty in the concept of social welfare," Journal of Political Economy, vol. 58, no. 4, pp. 328-346, 1950.

[79] Nigerian National Petroleum Corporation, "Oil Production," http://www.nnpcgroup.com/nnpcbusiness/upstreamventures/ oilproduction.aspx. 


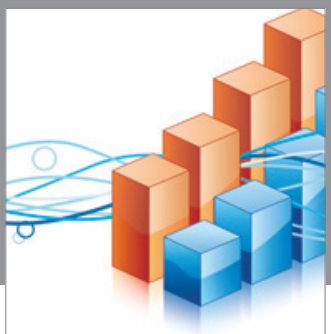

Advances in

Operations Research

vatem alat4

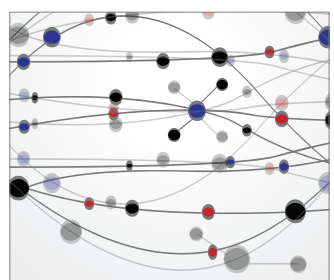

\section{The Scientific} World Journal
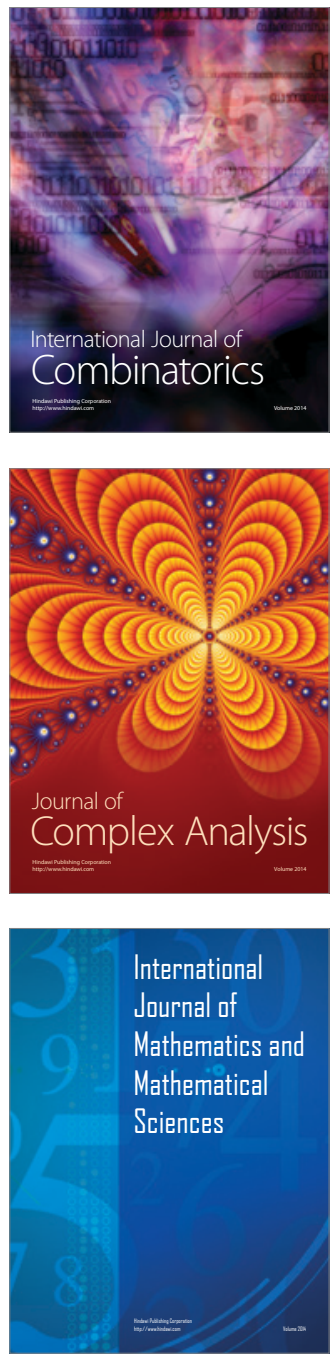
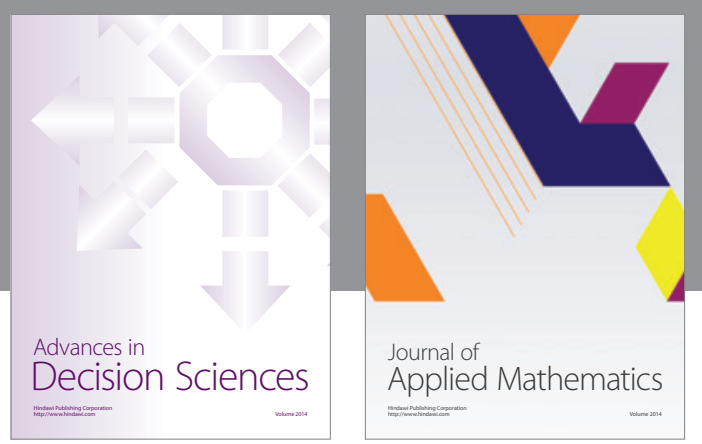

Algebra

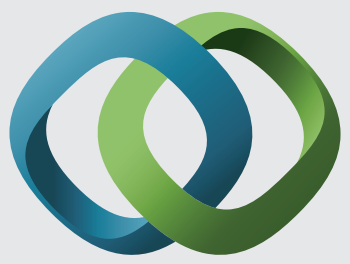

\section{Hindawi}

Submit your manuscripts at

http://www.hindawi.com
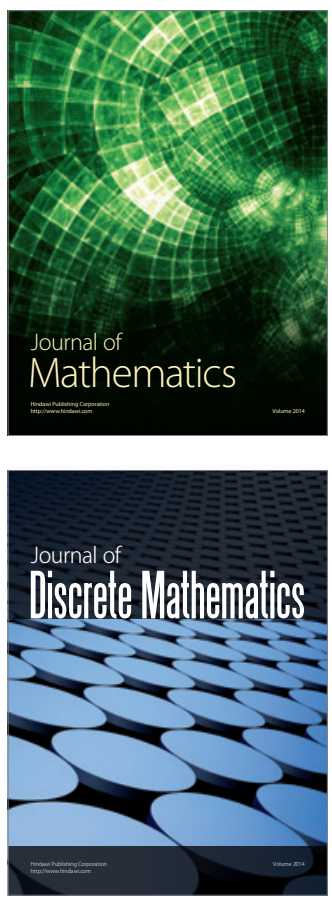

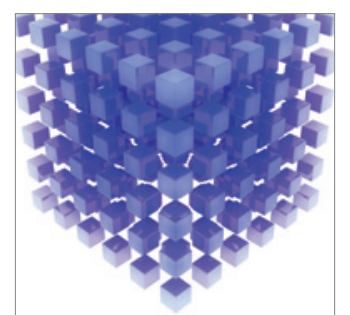

Mathematical Problems in Engineering
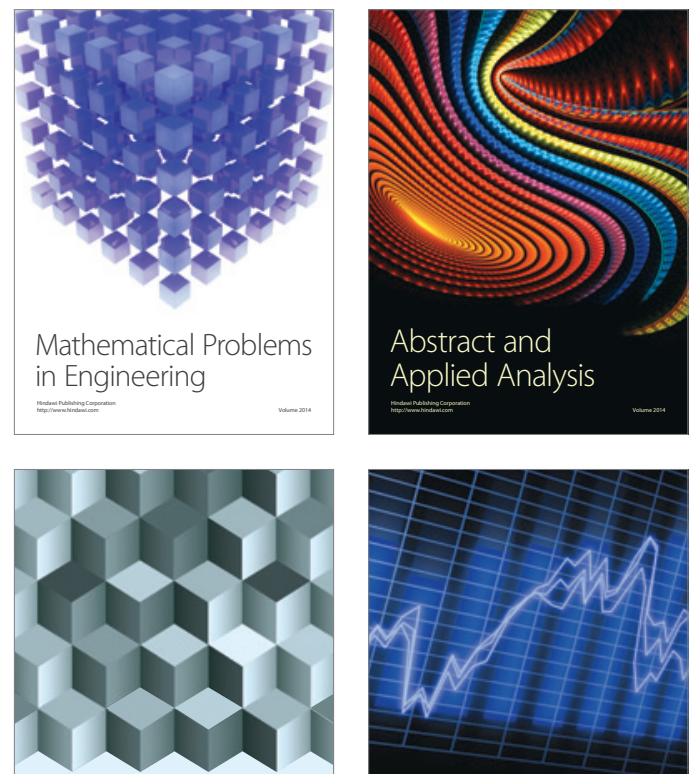

Journal of

Function Spaces

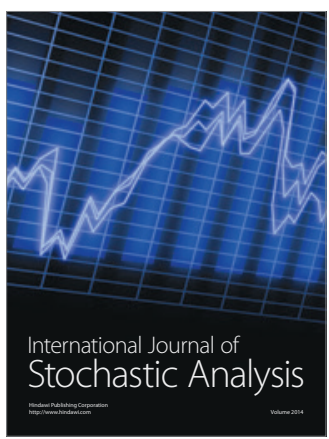

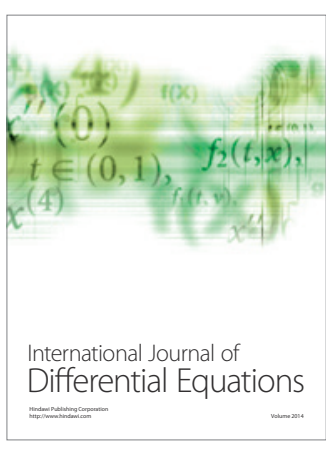
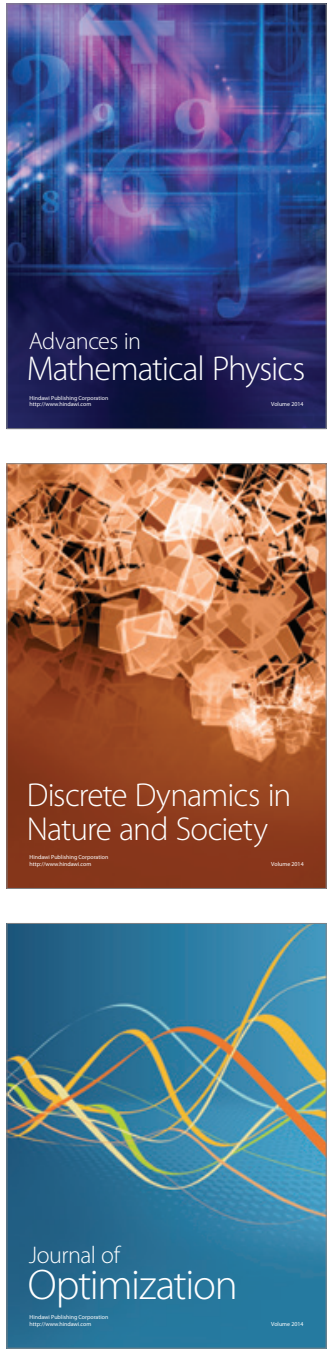